\title{
Clinical Care: Hallux Amputation Due to Disruption of Diabetes Services in COVID-19 Pandemic, Peshawar, Pakistan
}

\author{
Ahmedyar Hasan' ${ }^{1}$, Shagufta Zia ${ }^{2}$, Zainab Jamal' ${ }^{1}$ \\ ${ }^{1}$ AIMS Sugary Hospital, Hayatabad, Pakistan \\ ${ }^{2}$ Medcare Medical Center, Dubai, UAE \\ Email: shagufta.zia@medcarehospital.com
}

How to cite this paper: Hasan, A., Zia, S. and Jamal, Z. (2021) Clinical Care: Hallux Amputation Due to Disruption of Diabetes Services in COVID-19 Pandemic, Peshawar, Pakistan. Journal of Diabetes Mellitus, 11, 171-177.

https://doi.org/10.4236/jdm.2021.114013

Received: June 15, 2021

Accepted: November 5, 2021

Published: November 8, 2021

Copyright ( $\odot 2021$ by author(s) and Scientific Research Publishing Inc. This work is licensed under the Creative Commons Attribution International License (CC BY 4.0).

http://creativecommons.org/licenses/by/4.0/

\begin{abstract}
Diabetes mellitus is one of the most prevalent endocrine disorders associated with macro and micro vascular complications. Lower limb complications associated with diabetes including Diabetic Foot Ulcers (DFU) are a major public health issue worldwide. Novel Coronavirus (COVID-19) is a strain of coronavirus which causes illness in animals and humans. COVID-19 has significantly affected people with chronic medical conditions such as diabetes, hypertension, cardiovascular disease and cancer with severe illness and worse outcomes as well as disruption of their routine medical care provision. We presented a case-study of 59-year-old patient with diabetes and hypertension, with an unexpected DFU complication that resulted in big toe amputation. Therefore it is vital for us as health care professional to find innovative ways to ensure the continuity of medical care/service provision along with the fight of COVID-19.
\end{abstract}

\section{Keywords}

Diabetic Foot Ulcer, Amputation, COVID-19, Primary Health Care

\section{Background}

Diabetes mellitus is one of the most prevalent endocrine disorders associated with macro and micro vascular complications. According to IDF (International Diabetes Federation) 2017 estimates, currently 463 million people worldwide have diabetes and 55 million people with diabetes are living in the MENA region, and are estimated to increase to 108 million by 2045 . Currently $6.94 \%$ people have diabetes in Pakistan and it is estimated to rise to $8.45 \%$ by the year 2045 [1]. Prevalence of diabetes mellitus is increasing worldwide, especially in 
young and over-weight people in developing countries [2] [3]. According to World Health Organization (WHO), 150 million people are affected with type 2 diabetes mellitus and it will be doubled in the near future by 2025 [4]. The leading causes of hospitalization in patient with diabetes include infection, foot ulceration, and gangrene of foot amputation along with hypoglycemia and hyperglycemia emergencies [5].

Lower limb complications associated with diabetes including Diabetic Foot Ulcers (DFU) are a major public health issue worldwide [6] [7]. The IDF estimates that every 30 seconds, at least one limb is lost due to DFU in the world [1]. Patients with diabetes have $25 \%$ lifetime risk of developing DFU, with associated increased morbidity, mortality and poor quality of life [2] [8] [9] [10].

Diabetic foot ulcers contribute to high morbidity associated with low quality of life due to inability to perform normal daily activities due to loss of mobility and pain and economic burden due to loss of work [11]. Several factors contribute to the development and poor healing of foot ulcer in patients with diabetes, such as peripheral arterial disease, neuropathy, repeated trauma, pressure overload and foot pathologies such callosities and poor glycemic control [12]. Majority of the foot ulcers often lead to infection related necrosis, which in many cases results in the removal of skin of foot or lower-limb amputation [12]. Such radical complications associated with diabetes are more common in deviling countries due to lack of disease understanding or awareness, various socio-cultural practices like working or walking bear-feet, longer duration of disease, and poor glycemic control both due to lack of baseline disease knowledge as well as poverty and inability to afford medications regularly for life time.

As compared to normal population lower-limb amputations are 10-30 times more common in patients with diabetes [13]. Foot ulcer prevalence can be reduced drastically by improving patients understating of their disease, continuous blood glucose monitoring and regular low-cost health care provision with treatment supply, with regular feet checks. Various measures such as infection control, reconstruction of blood supply, reducing pressure on the affected limb and improvement of ulcer repair with surgical treatment can reduce foot ulcer up to $80 \%$ [14].

Non-communicable diseases (NCDs) kill 41 million people every year. Around 15 million adults ( 30 - 69 years old) die every year from NCDs, and majority $85 \%$ of such mortality is in Low-income and middle-income countries of the world. NCDs services has been adversely affected and significantly disrupted due to Novel Coronavirus (COVID-19) pandemic [15]. Novel Coronavirus is a strain of coronavirus which cause illness in animals and humans. In humans, they cause respiratory infections ranging from minor cold and flu like symptoms to severe pneumonia. It was broken out in a cluster of people with pneumonia symptoms in Wuhan city, Hubei province of China.

The main objective of this case report was to

1) Highlight the negative effect of COVID-19 pandemic on people lives with chronic diseases and lifelong consequences with a preventable and curable disa- 
bility.

2) An unexpected event in the course of treating a patient with diabetes, due to COVID-19 disrupted services.

\section{Clinical Case}

A 59-year-old married male, with six children, diagnosed with type-2 diabetes mellitus (DM2) for 28 years, attended AIMS Sugar Hospital, Peshawar, in Pakistan with an oozing left foot wound on $16^{\text {th }}$ June 2020 . He was regularly attending the outpatient department (OPD) of our hospital, every three to four months for his diabetes and hypertension prescription and routine blood tests since July 2019. In November 2019, he had a foot ulcer which was treated and it healed completely after a few weeks. His medication includes OHA (Oral Hypoglycemic Agents, Glucophage), Insulin Humalog injection, Losartan 50 mg, Losartan 50 $\mathrm{mg}$ and Aspirin $75 \mathrm{mg}$ daily. He is driving a Reksha for living (driver, as a profession). The patient lives 60 kilometers away from our facility, so visiting our Hospital is a difficult task.

In April 2020, he developed a left hallux injury with an open skin wound and was taking care of it himself for the first few weeks. Our facility was closed due to COVID-19 pandemic lockdown so he did not visit us. However, he tried to go to a local health care facility and due to the COVID-19 pandemic, only emergency services were available and he was sent back home with a skin dressing and medication but no follow-up was conducted. On the $30^{\text {th }}$ of May, he had developed gangrene of the left hallux and had no choice but to undergo a left hallux amputation. He visited us on the $16^{\text {th }}$ of June with an infected surgical wound on left foot (Figure 1(a)). Complex skin dressing and a change of antibiotics were given along with blood tests. His HbAlc was high (9.9\%) and his random blood glucose levels were $188 \mathrm{mg} / \mathrm{dl}$. He was advised to visit AIMS Sugar Hospital weekly for skin dressing and his insulin dose was also altered. On the $20^{\text {th }}$ of July, his wound had completely healed (Figure 1(b)) and his HbAlc was improved to $6.9 \%$.

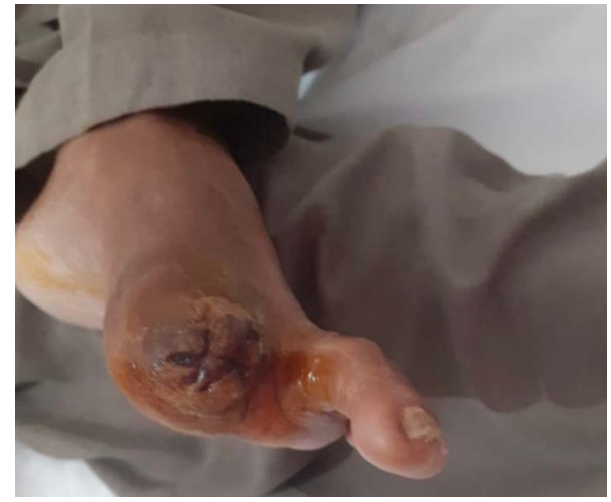

(a)

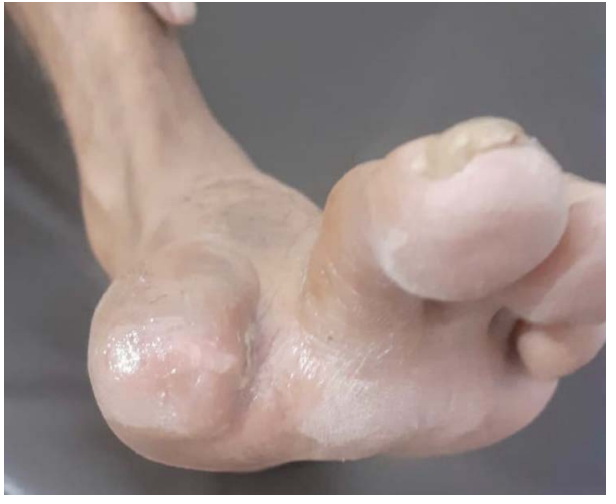

(b)

Figure 1. (a) Infected Left hallux upon initial visit to Hospital (16th of June, 2020). (b) Healed Left hallux (20th of July, 2020). 


\section{Discussion}

DFU and foot complications are completely preventable, and the frequency of lower limb amputations can be lowered by $49 \%-87 \%$ by preventing the development of DFU and early detection with appropriate management [16]. The prevalence of DFU can be reduced by $44 \%$ - $85 \%$ with early detection and appropriate treatment [17] [18]. Risk factors associated with DFU and death include increasing age, male gender, peripheral vascular disease, peripheral neuropathy, and renal disease [19]. Other less obvious risk factors include male gender, recurrent foot infections, ulcers, abscesses, osteomyelitis, and retinopathy associated with diabetes [16]. Chaturvedi et al. [20] also suggested that elevated levels of blood glucose and triglyceride and the presence of retinopathy are the key risk factors for amputation.

Research studies have reported high incidence of foot amputation in male gender [16] [21] and [22]. Bhawna et al. (2019) have shown that DFU is associated with longer duration of disease, oral anti-diabetic therapy, smoking, hyperlipidemia, hypertension, and history of ischemic heart disease (IHD), cerebrovascular stroke, peripheral ischemia, and diabetic nephropathy, and retinopathy in Pakistan [16]. However, Hippisley-Cox and Coupland (2016), reported that metformin therapy in patients with diabetes was associated with $30 \%$ of amputation as compared to $64 \%$ of lower extremity amputations in patients who were in insulin therapy [23]. Smoking, high cholesterol and high blood pressure were shown to be associated with diabetic foot amputation and it was shown that smoking cessation can serve as a protective measure against diabetic foot amputation [24] [25] [26] [27]. These factors lead to atherosclerosis promotion, which leads to peripheral ischemia and poor healing. Patients with diabetes are at a high risk of atherosclerotic peripheral vascular disease. Furthermore, Calle-Pascual (2001) reported that limb ischemia and peripheral vascular disease has been associated with amputation in patients with diabetic foot lesions [28]. Peripheral vascular disease or ischemia is associated with diabetes nephropathy and amputation in patients with diabetes. Margolis et al. (2008) reported that the risk of foot amputation increases in patients with both diabetes and chronic kidney disease (CKD, by 2 to 6 times, as compared to patients who have only diabetes [29]. Such an increase is related to high creatinine levels in CKD patients.

Diabetic foot lesions are responsible for health and socioeconomic issues, with adverse effects on the quality of life, and a serious economic burden on healthcare system. Foot amputations incidence can be reduced with early recognition of high-risk patients, optimum control of patient risk factors, and a multidisciplinary approach toward the management of foot-related lesions in patients with diabetes.

\section{Conclusions}

The incidence of foot amputation in patients with diabetes is high. Crucial risk factors include male gender, smoking, hyperlipidemia, hypertension, cardiac 
history, and the coexistence of diabetic nephropathy and retinopathy. Lower limb amputation in diabetes is a preventable complication. It needs individual patient care, early recognition of risk factors, and a multidisciplinary approach to manage diabetic foot lesions. Identifying risk factors will help in providing high-risk patients with the right care for early wound healing and for preventing any worse outcome.

Our "Diabetes circle of care" model at the community level is designed to provide cost-effective care to under privileged people with diabetes. This service allows patients to receive all diabetes related checks (Diet, eye, feet, dental and gum) under one roof, including feet exam for every new patient and repeat exam every 6 months for all registered patients. Patients at risk of developing DFU can easily be identified by clinical foot examination during their follow-up [30]. Early screening of high-risk patients is crucial to prevent development of foot ulcers and its associated morbidity.

People with chronic medical conditions such as diabetes, hypertension, cardiovascular disease and cancer are at higher risk of severe COVID-19 related illness and death. On the other hand, people with NCDs were more adversely affected due to the disruption of medical care provision such as medicine collection, laboratory tests and unexpected complications and care during this pandemic. Therefore, it is crucial for health care providers to find innovative ways to ensure the continuity of medical care and service along with the fight against COVID-19.

- We have started a telehealth service at AIMS Sugar Hospital to reduce such lifelong consequences of delayed medical care. Furthermore, we have employed a foot care coordinator to establish pathways and standard protocols for our diabetes patients with DFU to improve patient-nurse communication.

- We have also produced an educational leaflet in the local language (Urdu) which guides patients on foot care and increases awareness of foot complications.

- We hope that these steps taken can help to improve the well-being of our patients, and that other healthcare providers can learn from our experience.

\section{Acknowledgements}

We would like to acknowledge the cooperation and long term commitment of Diabetes Association Pakistan with AIMS in the provision of low cost diabetes care to our community through Sugar Hospital in Hayatabad. We are very grateful to our partner (District Government), in our outreach community camps project. We are also thankful to our dedicated staff, volunteers, including medical students from different medical schools, community workers who are helping us on a regular basis in different events, and organizations related to diabetes since 2014. In this publication, we are most grateful to our Community Program Unit staff for their contribution. 


\section{Conflicts of Interest}

The authors declare no conflicts of interest regarding the publication of this paper.

\section{References}

[1] International Diabetes Federation (2017) IDF Diabetes Atlas, 8. International Diabetes Federation, Brussels. http://www.diabetesatlas.org

[2] Singh, N., Armstrong, D.G. and Lipsky, B.A. (2005) Preventing Foot Ulcers in Patients with Diabetes. Journal of the American Medical Association, 293, 217-228. https://doi.org/10.1001/jama.293.2.217

[3] Fatima, E., Ashfaq, A. and Kamran, H. (2018) Prevalence of Diabetic Foot Ulcer in Lahore, Pakistan: A Cross Sectional Study. AJAHS, 3, 34-38.

[4] King, H., Aubert, R.E. and Herman, W.H. (1998) Global Burden of Diabetes, 1995-2025: Prevalence, Numerical Estimates, and Projections. Diabetes Care, 21, 1414-1431. https://doi.org/10.2337/diacare.21.9.1414

[5] Boulton, A.J., Vileikyte, L., Ragnarson-Tennvall, G. and Apelqvist, J. (2005) The Global Burden of Diabetic Foot Disease. The Lancet, 366, 1719-1724. https://doi.org/10.1016/S0140-6736(05)67698-2

[6] Wu, S.C., Driver, V.R., Wrobel, J.S. and Armstrong, D.G. (2007) Foot Ulcers in the Diabetic Patient, Prevention and Treatment. Vascular Health and Risk Management, 3, 65-76.

[7] Amin, N. and Doupis, J. (2016) Diabetic Foot Disease: From the Evaluation of the "Foot at Risk" to the Novel Diabetic Ulcer Treatment Modalities. World Journal of Diabetes, 7, 153-164. https://doi.org/10.4239/wjd.v7.i7.153

[8] Chammas, N.K., Hill, R.L.R. and Edmonds, M.E. (2016) Increased Mortality in Diabetic Foot Ulcer Patients: The Significance of Ulcer Type. Journal Diabetes Research, 1-7. https://doi.org/10.1155/2016/2879809

[9] Bild, D.E., Selby, J.V., Sinnock, P., Browner, W.S., Braveman, P. and Showstack, J.A. (1989) Lower-Extremity Amputation in People with Diabetes: Epidemiology and Prevention. Diabetes Care, 12, 24-31. https://doi.org/10.2337/diacare.12.1.24

[10] Nongmaithem, M., Bawa, A.P., Pithwa, A.K., Bhatia, S.K., Singh, G. and Gooptu, S. (2016) A Study of Risk Factors and Foot Care Behavior among Diabetics. Journal of Family Medicine and Primary Care, 5, 399-403. https://doi.org/10.4103/2249-4863.192340

[11] Boulton, A.J. (2008) The Diabetic Foot: Grand Overview, Epidemiology and Pathogenesis. Diabetes/ Metabolism Research and Reviews, 24, S3-S6. https://doi.org/10.1002/dmrr.833

[12] Berendt, A.R. and Lipsky, B.A. (2005) Infection in the Diabetic Foot. Clinical Care of the Diabetic Foot, 23, 90-98.

[13] Peters, E.J. and Lipsky, B.A. (2013) Diagnosis and Management of Infection in the Diabetic Foot. Medical Clinics, 97, 911-946. https://doi.org/10.1016/j.mcna.2013.04.005

[14] Assaad-Khalil, S.H., Zaki, A., Rehim, A.A., Megallaa, M.H., Gaber, N., Gamal, H. and Rohoma, K.H. (2015) Prevalence of Diabetic Foot Disorders and Related Risk Factors among Egyptian Subjects with Diabetes. Primary Care Diabetes, 9, 297-303. https://doi.org/10.1016/j.pcd.2014.10.010

[15] https://www.who.int/news-room/detail/01-06-2020-covid-19-significantly-impactshealth-services-for-noncommunicable-diseases 
[16] Nanwani, B., Shankar, P., Kumar, R. and Shaukat, F. (2019) Factors of Diabetic Foot Amputation in Pakistani Type II Diabetes Individuals. Cureus, 11, e4795. https://doi.org/10.7759/cureus.4795

[17] Federation ID (2013) IDF Diabetes Atlas. International Diabetes Federation, Brussels.

[18] Holstein, P., Ellitsgaard, N., Bornefeldt Olsen, B. and Ellitsgaard, V. (2000) Decreasing Incidence of Major Amputations in People with Diabetes. Diabetologia, 43, 844-847. https://doi.org/10.1007/s001250051459

[19] Jupiter, D.C., Thorud, J.C., Buckley, C.J. and Shibuya, N. (2016) The Impact of Foot Ulceration and Amputation on Mortality in Diabetic Patients. I: From Ulceration to Death, a Systematic Review. International Wound Journal, 13, 892-903. https://doi.org/10.1111/iwj.12404

[20] Chaturvedi, N., Stevens, L.K., Fuller, J.H., Lee, E.T. and Lu, M. (2001) Risk Factors, Ethnic Differences and Mortality Associated with Lower-Extremity Gangrene and Amputation in Diabetes: The WHO Multinational Study of Vascular Disease in Diabetes. Diabetologia, 44, 65-71. https://doi.org/10.1007/PL00002941

[21] Hamalainen, H., Rönnemaa, T., Halonen, J.P. and Toikka, T. (1999) Factors Predicting Lower Extremity Amputations in Patients with Type 1 or Type 2 Diabetes Mellitus: A Population-Based 7-Year Follow-Up Study. Journal of Internal Medicine, 246, 97-103. https://doi.org/10.1046/j.1365-2796.1999.00523.x

[22] Tseng, C.H. (2006) Prevalence of Lower-Extremity Amputation among Patients with Diabetes Mellitus: Is Height a Factor? CMAJ, 174, 319-323.

https://doi.org/10.1503/cmaj.050680

[23] Hippisley-Cox, J. and Coupland, C. (2016) Diabetes Treatments and Risk of Amputation, Blindness, Severe Kidney Failure, Hyperglycaemia, and Hypoglycaemia: Open Cohort Study in Primary Care. BMJ, 352, 1450. https://doi.org/10.1136/bmj.i1450

[24] Liu, M., Zhang, W., Yan, Z. and Yuan, X. (2017) Smoking Increases the Risk of Diabetic Foot Amputation: A Meta-Analysis. Experimental and Therapeutic Medicine, 15, 1680-1685. https://doi.org/10.3892/etm.2017.5538

[25] Young, B.A., Lin, E., Von Korff, M., et al. (2008) Diabetes Complication Severity Index and Risk of Mortality, Hospitalization and Healthcare Utilization. The American Journal of Managed Care, 14, 15-24.

[26] Lee, J.S., Lu, M.L., Lee, V.S., Russel, D., Bahr, C. and Lee, E.T. (1993) Lower-Extremity Amputation: Incidence, Risk Factors and Mortality in the Oklahoma Indian Diabetes Study. Diabetes, 42, 876-882. https://doi.org/10.2337/diabetes.42.6.876

[27] Resnick, H.E., Carter, E.A., Sosenko, J.M., et al. (2004) Incidence of Lower-Extremity Amputation in American Indians: The Strong Heart Study. Diabetes Care, 27, 1885-1891. https://doi.org/10.2337/diacare.27.8.1885

[28] Calle-Pascual, A.L., Garcia-Torre, N., Moraga, I., et al. (2001) Epidemiology of Nontraumatic Lower-Extremity Amputation in Area 7, Madrid, between 1989 and 1999: A Population-Based Study. Diabetes Care, 24, 1686-1689. https://doi.org/10.2337/diacare.24.9.1686

[29] Margolis, D.J., Hofstad, O. and Feldman, H.I. (2008) Association between Renal Failure and Foot Ulcer or Lower-Extremity Amputation in Patients with Diabetes. Diabetes Care, 31, 1331-1336. https://doi.org/10.2337/dc07-2244

[30] Zubair, M., Malik, A. and Ahmad, J. (2015) Diabetic Foot Ulcer: A Review. American Journal of Internal Medicine, 3, 28-49.

https://doi.org/10.11648/j.ajim.20150302.11 